\title{
Differentiation of Shigella by Esterase Electrophoretic Polymorphism
}

\author{
By $\mathrm{PH}_{\text {H. GOULlET* And B. PICARD }}$ \\ Laboratoire de Microbiologie, Faculté de Médecine Xavier Bichat (Université Paris VIn), \\ 16 rue Henri Huchard, 75018 Paris, France
}

(Received 9 September 1986; revised 7 November 1986)

The electrophoretic mobilities of four esterases (A, B, C and I) of 182 strains of Shigella dysenteriae, S. flexneri, S. boydii and S. sonnei were compared to those of 636 strains of Escherichia coli from various origins, including the Alkalescens Dispar group and enteroinvasive strains. Discriminant analysis of the distribution of esterases among the strains revealed that Shigella could be distinguished from $E$. coli by differences in the distribution of allozymes of esterases $\mathrm{C}$ and I. Principal components analysis distinguished four major clusters of Shigella strains corresponding to the following: $S$. dysenteriae serotype $1 ; S$. flexneri serotypes 1 to $5 ; S$. flexneri serotype 6 and $S$. boydii serotypes 2 and 4 ; and $S$. sonnei. The last three were characterized by distinct electrophoretic variants of carboxylesterase B, as judged by the twodimensional electrophoretic profile and titration curves. The distinct esterase pattern obtained for the strains of $S$. boydii serotype 13 substantiates the view that this serotype may constitute a new species.

\section{INTRODUCTION}

DNA hybridization studies have shown that Escherichia coli and Shigella (except $S$. boydii serotype 13) are part of the same genetic species (Brenner et al., 1972, 1973). However, numerical taxonomy, nutritional characterization and enzyme electrophoresis indicate that there are differences between these organisms (Johnson et al., 1975; Veron \& Le Minor, 1975; Ochman et al., 1983) and between the four taxospecies of Shigella [S. dysenteriae, S. flexneri, $S$. boydii and S. sonnei (Goullet, 1980; Dodd \& Jones, 1982)].

Previous work has demonstrated that four electrophoretically variable esterases - bands A, B, $\mathrm{C}$ and I - are produced both by $E$. coli and Shigella strains, and that variations in the number and mobility of these bands between Shigella strains define different esterase patterns which appear to be distinct for each species (Goullet, 1980). By comparing esterase mobilities of $E$. coli isolates obtained from three distinct sources (animal and human gastro-intestinal tracts and extraintestinal infections in man) we have shown that these three bacterial populations differ in their esterase electrophoretic polymorphism (Goullet \& Picard, 1986a), and that the frequency of strains showing slow mobilities of esterase $\mathbf{B}$ (pattern $\mathbf{B}_{2}$ ) is considerably higher when they originate from extra-intestinal infections than when they are obtained from the intestinal tract of healthy individuals (Goullet \& Picard, 1986a,b).

The aim of this work was to analyse esterase polymorphism in Shigella species and to describe the relationships of the esterase patterns of these organisms and those of $E$. coli. The study is composed of two major parts: (i) a comparison of the conventional electrophoresis (CE) data obtained from Shigella with those obtained from the three populations of $E$. coli previously

\footnotetext{
Abbreviations: AIS, animal intestinal strains; CE, conventional electrophoresis; DFP, di-isopropyl fluorophosphate; $E_{v}$, electrophoretic type; GDC, genetic diversity coefficient; HES, human extra-intestinal infection strains; HIS, human intestinal strains; IEF, isoelectrofocusing; $M_{F}$, electrophoretic mobility; $W E_{v}$, weighted electrophoretic type.
} 
Table 1. Strains of Shigella examined

The strain abbreviations are as follows: CNS, Centre National des Shigella (strains provided by Dr Toucas, Institut Pasteur, Paris, France); NCTC, National Collection of Type Cultures; CIP, Collection de l'Institut Pasteur, Paris, France; NCDC, National Centers for Disease Control, Atlanta, USA; PHLL, Public Health Laboratory, Leicester, UK.

\section{S. dysenteriae}

\begin{tabular}{clclcl} 
Serotype & \multicolumn{1}{c}{ Strain } & Serotype & \multicolumn{1}{c}{ Strain } & Serotype & \multicolumn{1}{c}{ Strain } \\
1 & CNS 12.77 & 1 & CIP 53.136 & 5 & CIP 57.42 \\
1 & CNS 15.77 & 2 & CNS 2.64 & 6 & NCTC 9762* \\
1 & NCTC 4837* & 2 & CNS 3.76 & 6 & NCTC 9956* \\
1 & NCTC 8571* & 2 & CNS 4.77 & 7 & CNS 31.73 \\
1 & Sakazakii 4379-60* & 2 & CNS 5.77 & 7 & CIP 52.123 \\
1 & CIP 56.33 & 3 & CIP 53.127 & 8 & NCTC 8599* \\
1 & CIP 62.17 & 3 & CNS 17.77 & 8 & NCTC 9346* \\
1 & CIP 58.1 & 4 & CIP 59.2 & 9 & CNS 5.76 \\
1 & CIP 52.27 & 4 & CNS 6.77 & 9 & CIP 58.25 \\
1 & CIP 55.90 & 5 & CNS 30.73 & 10 & NCTC 9351 \\
1 & CIP 54.95 & 5 & CIP 52.120 & 10 & CIP 58.27
\end{tabular}

S. flexneri

\begin{tabular}{|c|c|c|c|c|c|}
\hline Serotype & Strain & Serotype & Strain & Serotype & Strain \\
\hline 1 & CNS 9.76 & 2 & CNS 464.80 & 6 & CNS 14.79 \\
\hline 1 & CNS 8.77 & 2 & CNS 468.80 & 6 & CNS 66.79 \\
\hline 1 & CNS 401.77 & 3 & CNS 6.77 & 6 & NCDC 2924.71 \\
\hline 1 & NCDC 1921.71 & 3 & CNS 418.77 & 6 & CNS 7590.75 \\
\hline 1 & CNS 316.80 & 3 & NCDC 2783.71 & 6 & CNS 190.77 \\
\hline 1 & CNS 317.80 & 3 & CNS 178.80 & 6 & CNS 238.78 \\
\hline 1 & CNS 367.80 & 3 & CNS 250.80 & 6 & CNS 347.78 \\
\hline 1 & CNS 431.80 & 3 & CNS 319.80 & 6 & CNS 371.78 \\
\hline 1 & CNS 449.80 & 3 & CNS 400.80 & 6 & CNS 415.78 \\
\hline 1 & CNS 451.80 & 3 & CNS 422.80 & 6 & CNS 462.78 \\
\hline 1 & CNS 452.80 & 3 & CNS 437.80 & 6 & CNS 74.79 \\
\hline 1 & CNS 471.80 & 4 & CNS 3.75 & 6 & CNS 99.79 \\
\hline 2 & CNS 18.70 & 4 & NCDC 6603.63 & 6 & CNS 185.79 \\
\hline 2 & CNS 20.76 & 4 & CNS 441.78 & 6 & CNS 294.79 \\
\hline 2 & CNS 416.77 & 4 & CNS 109.79 & 6 & CNS 10.80 \\
\hline 2 & CNS 446.77 & 4 & CNS 157.80 & 6 & CNS 91.80 \\
\hline 2 & NCDC 2747.71 & 4 & CNS 399.80 & 6 & CNS 222.80 \\
\hline 2 & CNS 270.80 & 4 & CNS 461.80 & 6 & CNS 233.80 \\
\hline 2 & CNS 293.80 & 4 & CNS 465.80 & 6 & CNS 246.80 \\
\hline 2 & CNS 318.80 & 5 & NCDC 6154.61 & 6 & CNS 254.80 \\
\hline 2 & CNS 362.80 & 5 & CNS 236.78 & 6 & CNS 285.80 \\
\hline 2 & CNS 389.80 & 5 & CNS 237.78 & 6 & CNS 340.80 \\
\hline 2 & CNS 390.80 & 5 & CNS 288.78 & 6 & CNS 358.80 \\
\hline 2 & CNS 401.80 & 5 & CNS 86.80 & 6 & CNS 360.80 \\
\hline 2 & CNS 430.80 & 6 & CNS 6.74 & 6 & CNS 364.80 \\
\hline 2 & CNS 432.80 & 6 & CNS 3.77 & 6 & CNS 463.80 \\
\hline 2 & CNS 441.80 & 6 & CNS 445.77 & 6 & CNS 50.78 \\
\hline 2 & CNS 450.80 & 6 & CNS 302.78 & 6 & CNS 388.78 \\
\hline 2 & CNS 454.80 & 6 & CNS 354.78 & & \\
\hline
\end{tabular}


Table 1. (continued)

\begin{tabular}{|c|c|c|c|c|c|}
\hline & & & boydii & & \\
\hline Serotype & Strain & Serotype & Strain & Serotype & Strain \\
\hline 1 & CIP 54.73 & 5 & CNS 19.80 & 11 & NCTC $9360^{*}$ \\
\hline 1 & CNS 32.70 & 6 & NCTC $9771^{*}$ & 12 & NCTC $9772^{*}$ \\
\hline 1 & CNS 42.80 & 7 & NCTC $9333^{*}$ & 13 & NCTC $9361^{\circ}$ \\
\hline 2 & CIP 54.74 & 8 & CIP 56.35 & 13 & CIP 58.21 \\
\hline 2 & CNS 16.76 & 9 & CIP 57.43 & 13 & CIP 58.22 \\
\hline 3 & PHLL 37746/75* & 9 & CIP 2.77 & 13 & CIP 76.114 \\
\hline 3 & NCTC $9329^{*}$ & 10 & CIP 599 & 13 & CIP 76.115 \\
\hline 4 & CIP 54.76 & 10 & CNS 12.77 & 14 & NCTC $9766^{*}$ \\
\hline 4 & CNS 5.77 & 10 & CNS 12.80 & 14 & NCTC $8592^{*}$ \\
\hline 5 & CIP 56.36 & 11 & CNS 41.80 & 15 & NCTC $8590^{*}$ \\
\hline 5 & CNS 7.77 & 11 & NCTC 9321 & 15 & NCTC $9365^{*}$ \\
\hline 5 & CNS 21.77 & 11 & CIP 56.18 & & \\
\hline
\end{tabular}

S. sonnei

\begin{tabular}{lll}
\multicolumn{1}{c}{ Strain } & \multicolumn{1}{c}{ Strain } & \multicolumn{1}{c}{ Strain } \\
CNS P.273 & CNS 4.76 & CNS 191.77 \\
CNS 46.70 & CNS 2.77 & CNS 217.77 \\
CNS 350.73 & CNS 11.77 & CNS 241.77 \\
CNS 413.73 & CNS 13.77 & CNS 586.77 \\
CNS 43.74 & CNS 15.77 & CNS 1.78 \\
CNS 5.75 & CNS 16.77 & CNS 471.78 \\
CNS Tri 7.75 & CNS 18.77 & CNS 489.78 \\
CNS 20.75 & CNS 110.77 & CNS 570.78 \\
CNS NAJ. 76 & CNS 130.77 & CNS 423.79 \\
& & CNS 424.79
\end{tabular}

* Derivative of culture provided by Dr Jones, Department of Microbiology, The University, Leicester, UK.

investigated and with those from the Alkalescens Dispar group and entero-invasive $E$. coli strains; and (ii) a refined analysis of esterase $B$ variants by use of two-dimensional electrophoretic profiles (Goullet \& Picard, 1985) and titration curves (Rhigetti et al., 1978).

\section{METHODS}

Shigella strains. The test strains are shown in Table 1.

E. coli strains. Two hundred and eleven animal intestinal strains (AIS), 142 human intestinal strains (HIS), 257 extraintestinal infection strains (HES) and 14 Alkalescens Dispar group strains were analysed by Goullet (1980) and Goullet \& Picard (1986a); 12 entero-invasive E. coli strains from the serotypes 0136, 0115, 028, 0143 (two strains including strain 4608-58, Sansonetti et al., 1983), 0112, 042, 0159, 029, 0124, 025, 0152 were obtained from Dr Sansonetti (Service des Enterobacteries de l'Institut Pasteur de Paris, Professeur Le Minor).

Culture conditions. All isolates were cultured in Fernbach flasks containing $500 \mathrm{ml} \mathrm{L}$ broth (Lennox, 1955) without glucose. The flasks were shaken vigorously for $18 \mathrm{~h}$ at $37^{\circ} \mathrm{C}$ in a reciprocating water bath shaker set at about 70 oscillations $\min ^{-1}$.

Electrophoretic analysis. The preparation of extracts, inhibition by di-isopropyl fluorophosphate (DFP), heat inactivation, horizontal slab PAGE $(7 \%, \mathrm{w} / \mathrm{v}$, acrylamide; Tris/glycine buffer, $\mathrm{pH} 8 \cdot 6)$, estimation of electrophoretic mobility $\left(M_{F}\right)$, polyacrylamide gel isoelectrofocusing (IEF), determination of isoelectric points and esterase staining were described by Goullet (1973) and Goullet \& Picard (1985).

Each variant was designated as an allozyme. When an esterase was not detected in a strain, it was recorded as 'null allozyme' (and scored 0). Each distinctive combination of allozymes for the four varieties of esterases was designated as an electrophoretic type $\left(E_{1}\right)$. In principal components analyses, the weighted electrophoretic type $\left(W E_{\mathrm{t}}\right)$ designated the number of strains showing the same $E_{\mathrm{t}}$ (Goullet \& Picard, 1986a).

Combined IEF-CE titration curves. Details of the technique used are described in Rhigetti et al. (1978). The essential features are that, in the first step, a pH gradient ( $\mathrm{pH} 3.5$ to 10) is formed across the gel; the crude extract is then applied in a groove running across the gradient, and electrophoresis is done perpendicular to this gradient. Sigmoidal $\mathrm{pH}$ mobility curves approximating to the titration curves of esterase are visualized by the specific staining procedure. 
Statistical analyses. Principal components analyses and discriminant analysis were done using the Biomedical Programs of the University of California (Dixon, 1981). The electrophoretic data were converted into binary code by considering each allozyme as a variable, occuring in either of two states, i.e. present $=1$ or absent $=0$ [for full details see Ochman et al. (1983) and Goullet \& Picard (1986a)].

\section{RESULTS}

\section{Comparative distribution of esterase mobilities in Shigella and E. coli strains}

A comparison of the distribution of allozymes of esterase A (Table 2) showed that a greater proportion of Shigella strains than E. coli strains possessed allozyme A-81; the opposite was true for allozyme A-75 and for allozyme A-78. The most frequently observed allozymes of esterase B produced by Shigella had the same mobilities as the three most frequent allozymes of pattern $\mathbf{B}_{1}$ of $E$. coli (Goullet \& Picard, $1986 a, b$ ). All Shigella strains had fast-migrating esterase B except for two strains of serotypes 2 and 3 of $S$. flexneri, where esterase B was slow-migrating. Considerably higher proportions of allozymes C-57, C-59 and C-61 were found for Shigella esterase $\mathrm{C}$ than for esterase $\mathrm{C}$ from the $E$. coli strains. Contrasting with the Gaussian distribution of 20 allozymes from $E$. coli, esterase I of Shigella had only two allozymes: I-68 (detected in less than $10 \%$ of E. coli strains) was encountered in more than $50 \%$ of Shigella strains; I-65 (detected in only one $E$. coli strain) was observed in $37(17 \%)$ Shigella strains. Thus, some allozymes of esterases $\mathrm{C}$ and I appeared significantly more frequently in Shigella than in $E$. coli strains. The number of null allozymes scored for esterases A, B and I was higher for Shigella than for E. coli.

\section{Genetic diversity of Shigella}

The genetic diversity coefficients (GDCs) (Nei, 1978, Selander et al., 1986) determined for the four taxospecies of Shigella distinguished among isolates are shown in Table 3. The mean genetic diversity was lower for $S$. sonnei than for the other taxospecies.

\section{Electrophoretic types in the four taxospecies of Shigella}

The 182 Shigella strains contained 23 distinct combinations of allozymes for the four esterases (electrophoretic types B, A, C, I: $E_{\mathrm{tBACl}}$ ) (Table 4). All strains of $S$. sonnei and of $S$. flexneri had at least three esterases whereas some strains of $S$. boydii and of $S$. dysenteriae had only one or two esterases. Each taxospecies was characterized by distinct electrophoretic types with the exception of 15 strains of $S$. boydii (serotypes 3, 5, 7, 9, 11 and 15) and nine strains of $S$. dysenteriae (serotypes 2, 5 and 8 ) which produced only esterase C. However, several strains of these serotypes were differentiated by an additional esterase band. $S$. sonnei appeared to be relatively electrophoretically homogeneous, while $S$. flexneri was clearly separated into two groups: one for serotypes 1 to 5 and another for serotype 6 (Goullet, 1980; Goullet et al., 1983). This latter group resembled strains of $S$. boydii serotypes 2 and 4 . $S$. boydii serotype 13 did not produce esterases B, A and I but five strains of this serotype had one esterase band at $M_{F} \simeq 70$ that hydrolysed $\alpha$ - and $\beta$-naphthyl acetates, $\alpha$-naphthyl butyrate and indoxyl acetate, and three strains had one esterase band at $M_{F} \simeq 72$ that hydrolysed $\beta$-naphthyl acetate and butyrate and indoxyl acetate. The activity of these two bands was resistant to DFP $\left(10^{-3} \mathrm{M}\right)$ but sensitive to heat $\left(10 \mathrm{~min}, 60^{\circ} \mathrm{C}\right)$. The strains of this serotype did not produce esterase $\mathrm{F}$ (Goullet, 1973, 1980). The strains of $S$. dysenteriae serotype 10 and a strain of $S$. dysenteriae serotype 7 produced esterase B which was not observed in the other serotypes (Goullet, 1980).

\section{Distinctive electrophoretic types of Shigella and E. coli}

The 12 entero-invasive $E$. coli strains exhibited 12 electrophoretic types (Table 5) which were distinct from the Shigella electrophoretic types. Of the $636 \mathrm{E}$. coli strains, there were 328 distinct electrophoretic types, including the 316 reported by Goullet \& Picard (1986a), plus five additional electrophoretic types of the Alkalescens Dispar group and seven of entero-invasive $E$. coli.

The electrophoretic relationships between Shigella and $E$. coli were analysed by comparing the $23 E_{\mathrm{tBACl}}$ of Shigella with strains of $E$. coli showing the corresponding $E_{\mathrm{t}}$ (Table 4). As the 
Table 2. Electrophoretic distribution of esterases A, B, C and I in E. coli and Shigella populations

The values given are the percentage of strains with each allozyme; particularly significant values are shown in bold type. NA, Null allozyme.

\begin{tabular}{|c|c|c|c|c|c|c|c|c|}
\hline \multirow[b]{2}{*}{$M_{F}$} & \multicolumn{2}{|c|}{ Esterase A } & \multicolumn{2}{|c|}{ Esterase B } & \multicolumn{2}{|c|}{ Esterase C } & \multicolumn{2}{|c|}{ Esterase I } \\
\hline & E. coli & Shigella & E. coli & Shigella & E. coli & Shigella & E. coli & Shigella \\
\hline 44 & & & & & 0.94 & & & \\
\hline 45 & & & & & & & & \\
\hline 46 & & & & & 1.41 & & & \\
\hline 47 & & & & & 0.15 & & & \\
\hline 48 & & & & & $9 \cdot 27$ & 1.09 & & \\
\hline 49 & & & & & & & & \\
\hline 50 & & & & & $1 \cdot 41$ & & & \\
\hline 51 & & & & & & & & \\
\hline 52 & & & & & $1 \cdot 41$ & & & \\
\hline 53 & & & & & $5 \cdot 34$ & & 0.15 & \\
\hline 54 & & & & & 1.41 & & & \\
\hline 55 & & & & & 21.06 & & $0 \cdot 15$ & \\
\hline 56 & & & & & 0.31 & & & \\
\hline 57 & & & 12.89 & & 10.84 & 48.90 & 0.62 & \\
\hline 58 & & & & & 0.15 & & 0.31 & \\
\hline 59 & & & & & 3.61 & 19.78 & 0.62 & \\
\hline 60 & & & $5 \cdot 34$ & & 19.65 & & $4 \cdot 71$ & \\
\hline 61 & & & & & 0.62 & $18 \cdot 13$ & 0.47 & \\
\hline 62 & & & $2 \cdot 35$ & 0.54 & $2 \cdot 51$ & 0.54 & $3 \cdot 30$ & \\
\hline 63 & & & 0.31 & & 0.47 & & 2.98 & \\
\hline 64 & & & & 0.54 & & & 0.47 & \\
\hline 65 & & & & & & & 0.62 & 17.58 \\
\hline 66 & & & 1.88 & & 0.31 & & 3.77 & \\
\hline 67 & & & 0.15 & & & & 0.47 & \\
\hline 68 & & & 9.59 & 17.03 & & & 9.90 & 51.64 \\
\hline 69 & & & & & & & & \\
\hline 70 & & & 48.89 & 17.03 & & & 31.28 & \\
\hline 71 & 0.47 & & & & & & & \\
\hline 72 & 0.31 & & 8.80 & $25 \cdot 27$ & & & $7 \cdot 23$ & \\
\hline 73 & & & $2 \cdot 35$ & & & & 4.08 & \\
\hline 74 & 0.15 & & 2.51 & & & & 1.57 & \\
\hline 75 & 48.74 & $29 \cdot 12$ & $0 \cdot 15$ & & & & 2.98 & \\
\hline 76 & & & & & & & & \\
\hline 77 & & & & & & & & \\
\hline 78 & 28.45 & 6.59 & & & & & $1 \cdot 10$ & \\
\hline 79 & & & & & & & & \\
\hline 80 & & & & & & & & \\
\hline 81 & $13 \cdot 20$ & 42.85 & & & & & & \\
\hline 82 & & & & & & & & \\
\hline 83 & 0.94 & & & & & & & \\
\hline NA & $7 \cdot 70$ & 21.44 & 4.71 & $39 \cdot 59$ & $19 \cdot 13$ & $11 \cdot 56$ & $23 \cdot 11$ & 30.78 \\
\hline
\end{tabular}

Table 3. Genetic diversity $(H)$ of esterases $A, B, C$ and $I$ in each of the four taxospecies of Shigella

$\mathrm{H}=1-\sum x_{\mathrm{i}}^{2}(n / n-1)$ where $x_{\mathrm{i}}$ is the frequency for each allozyme and $n$ the number of strains in each taxospecies.

\begin{tabular}{llllll} 
& \multicolumn{1}{c}{ A } & \multicolumn{1}{c}{ B } & \multicolumn{1}{c}{ C } & \multicolumn{1}{c}{ I } & Mean \\
S. sonnei & 0 & 0 & 0.51 & 0 & 0.127 \\
S. flexneri & 0.468 & 0.665 & 0.498 & 0 & 0.407 \\
S. boydii & 0.321 & 0.469 & 0.594 & 0.298 & 0.420 \\
S. dysenteriae & 0.667 & 0.165 & 0.597 & 0.298 & 0.431
\end{tabular}


Table 4. Distribution of the esterase electrophoretic types among the strains of the four taxospecies of Shigella and their correspondence with those of the $636 \mathrm{E}$. coli strains

\begin{tabular}{|c|c|c|c|c|c|c|c|}
\hline \multirow[b]{2}{*}{ Taxospecies } & \multirow[b]{2}{*}{ Serotype } & \multirow{2}{*}{$\begin{array}{l}\text { No. of } \\
\text { strains }\end{array}$} & \multirow{2}{*}{$\begin{array}{c}E_{\mathrm{tBACI}} \text { of } \\
\text { Shigella }\end{array}$} & \multicolumn{4}{|c|}{ having the same $E_{1}$ as Shigella* } \\
\hline & & & & $E_{\mathrm{IBA}}$ & $E_{\mathrm{tBAC}}$ & $E_{\mathrm{tBAl}}$ & $E_{\mathrm{tBACI}}$ \\
\hline S. sonnei & & $\begin{array}{r}16 \\
1 \\
11\end{array}$ & $\left.\begin{array}{llll}70 & 81 & 61 & 65 \\
70 & 81 & 62 & 65 \\
70 & 81 & 0 & 65\end{array}\right\}$ & $35(5.5 \%)$ & $\begin{array}{l}0 \\
1(0 \cdot 15 \%) \\
2(0.30 \%)\end{array}$ & $\begin{array}{l}0 \\
0 \\
0\end{array}$ & $\begin{array}{l}0 \\
0 \\
0\end{array}$ \\
\hline S. flexneri & $\begin{array}{l}1-5 \\
1 \\
1 \\
2 \\
2,3,5\end{array}$ & $\begin{array}{r}30 \\
1 \\
1 \\
1 \\
20\end{array}$ & 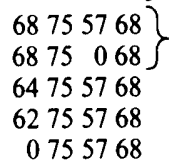 & $\begin{array}{l}38(5.97 \%) \\
0 \\
4(0.63 \%) \\
19(3 \%)\end{array}$ & $\begin{array}{l}4 \\
5(0.78 \%) \\
0 \\
0 \\
1(0.15 \%)\end{array}$ & $\begin{array}{l}0 \\
1(0 \cdot 15 \%) \\
0 \\
0 \\
4(0.62 \%)\end{array}$ & $\begin{array}{l}0 \\
1(0 \cdot 15 \%) \\
0 \\
0 \\
0\end{array}$ \\
\hline S. flexneri & $\begin{array}{l}6 \\
6\end{array}$ & $\begin{array}{r}31 \\
2\end{array}$ & 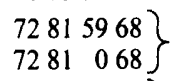 & $27(4 \cdot 25 \%)$ & $\begin{array}{l}0 \\
1(0 \cdot 15 \%)\end{array}$ & $\begin{array}{l}6(0.94 \%) \\
0\end{array}$ & $\begin{array}{l}0 \\
0\end{array}$ \\
\hline S. boydii & $\begin{array}{l}2,4 \\
12 \\
6,10 \\
1,3,8 \\
14 \dagger \\
3,5,7,9,11,15 \ddagger \\
13 \S\end{array}$ & $\begin{array}{r}4 \\
1 \\
4 \\
4 \\
2 \\
15 \\
5\end{array}$ & 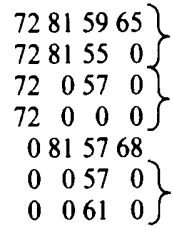 & $\begin{array}{l}7(1 \cdot 1 \%) \\
0 \\
0\end{array}$ & $\begin{array}{l}0 \\
19(3 \%) \\
0 \\
1(0 \cdot 15 \%) \\
0\end{array}$ & $\begin{array}{l}0 \\
5(0 \cdot 78 \%) \\
0 \\
1(0 \cdot 15 \%) \\
0\end{array}$ & $\begin{array}{l}0 \\
3(0.45 \%) \\
0 \\
1(0.15 \%) \\
0\end{array}$ \\
\hline S. dysenteriae & $\begin{array}{l}1 \\
10 \| \\
7 \\
3,6,7,9 \\
9 \\
3,4,6 \\
2,5,8 \text { व }\end{array}$ & $\begin{array}{r}12 \\
2 \\
1 \\
4 \\
1 \\
4 \\
9\end{array}$ & $\left.\begin{array}{rrrr}\begin{array}{r}0 \\
70\end{array} & 78 & 61 & 0 \\
70 & 08 & 0 \\
70 & 81 & 0 & 68 \\
0 & 81 & 57 & 68 \\
0 & 81 & 0 & 68 \\
0 & 81 & 57 & 0 \\
0 & 0 & 57 & 0\end{array}\right\}$ & $\begin{array}{l}11(1.7 \%) \\
27(4.25 \%) \\
35(5 \cdot 5 \%) \\
0\end{array}$ & $\begin{array}{l}0 \\
1(0 \cdot 15 \%) \\
2(0 \cdot 30 \%) \\
0\end{array}$ & $\begin{array}{l}4(0.62 \%) \\
8(1.25 \%) \\
3(0.45 \%) \\
0\end{array}$ & $\begin{array}{l}0 \\
0 \\
0\end{array}$ \\
\hline
\end{tabular}

* The 27 strains with an identical $E_{1 \mathrm{BA}}$ to $S$. boydii strains of serotypes 2, 4 and 12 were the same as those with an identical $E_{\mathrm{1BA}}$ to $S$. flexneri strains serotype 6; the 35 strains with an identical $E_{\mathrm{tBA}}$ to $S$. dysenteriae strains of serotype 7 were the same as those with an identical $E_{\mathrm{IBA}}$ to strains of $S$. sonnei; the two strains with an identical $E_{\mathrm{BAC}}$ to strains of $S$. dysenteriae serotype 7 were the same as those with an identical $E_{\mathrm{IBAC}}$ to strains of $S$. sonnei.

$\dagger$ Strains of $S$. boydii serotype 14 also exhibited a band at $M_{F} \simeq 72$ that hydrolysed $\alpha$-naphthyl butyrate and weakly hydrolysed $\alpha$-naphthyl and indoxyl acetates, and which was resistant to DFP $\left(10^{-3} \mathrm{M}\right)$.

$\ddagger$ Strains of $S$. boydii serotypes 3 and 5 , and strains of serotypes 9 and 15 , exhibited a faint band, at $M_{F} \simeq 76$ and $M_{F} \simeq 74$ respectively, that hydrolysed $\alpha$-naphthyl acetate.

$\S$ Strains of $S$. boydii serotype 13 exhibited two additional bands (see results).

$\|$ Strains of $S$. dysenteriae serotype 10 did not produce esterase $\mathrm{F}$.

If Three additional bands, resistant to DFP, were detected in strains of $S$. dysenteriae serotype 8: one band at $M_{F} \simeq 72$ from strain NCTC 9346 hydrolysed $\alpha$ - and $\beta$-naphthyl acetates; one band at $M_{F} \simeq 72$ from strain NCTC 8599 hydrolysed $\alpha$ - and $\beta$-naphthyl acetates, $\alpha$-naphthyl butyrate and indoxyl acetate (this band was resistant to heat); a third band at $M_{F} \simeq 70$ from the two strains hydrolysed $\alpha$ - and $\beta$-naphthyl butyrates.

Table 5. Electrophoretic types of esterases produced by the 12 entero-invasive E. coli strains

$\begin{array}{lrrrr}\text { Strain } & \text { B } & \text { A } & \text { C } & \text { I } \\ 0136 & 74 & 81 & 57 & 61 \\ 0115 & 73 & 78 & 63 & 68 \\ 028 & 72 & 81 & 57 & 60 \\ 0143(4608-58) & 70 & 78 & 57 & 60 \\ 0143 & 70 & 78 & 57 & 59 \\ 0112 & 70 & 78 & 0 & 0 \\ 042 & 70 & 75 & 60 & 68 \\ 0159 & 70 & 75 & 60 & 65 \\ 059 & 70 & 75 & 48 & 63 \\ 0124 & 68 & 75 & 50 & 0 \\ 025 & 66 & 81 & 60 & 0 \\ 0152 & 0 & 75 & 48 & 0\end{array}$



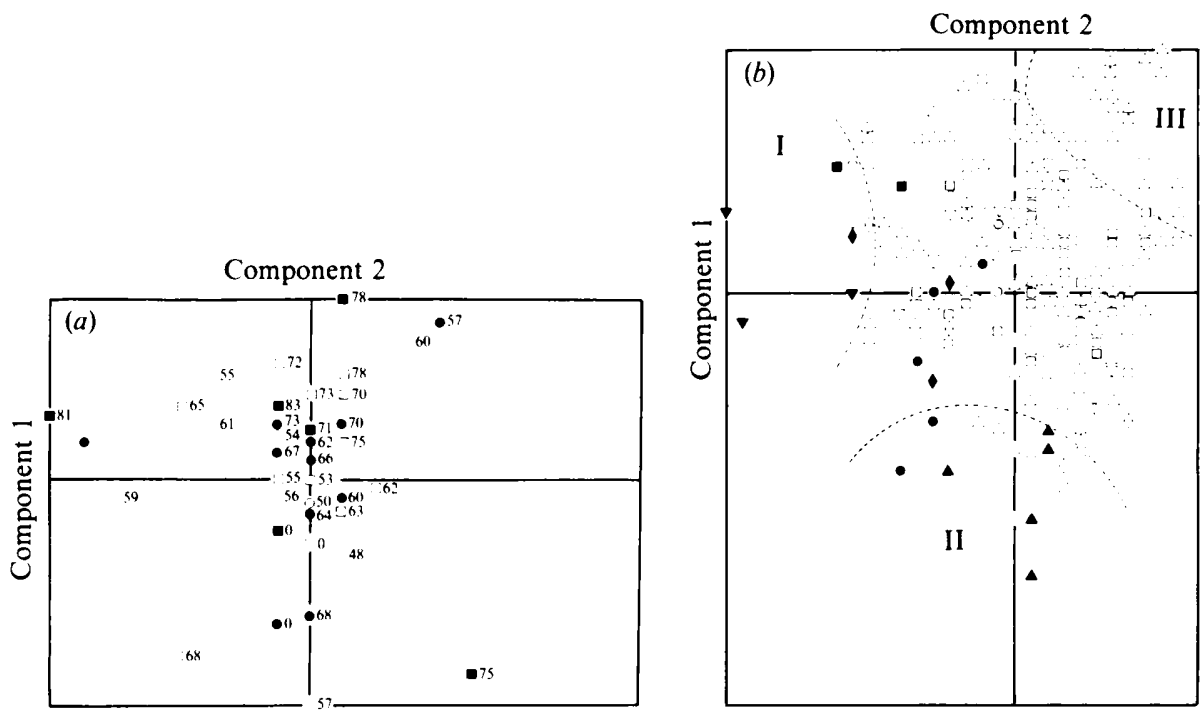

Fig. 1. Principal components analysis of the 175 Shigella strains and of the 636 E. coli strains. (a) Plot of score of allozymes of the four esterases for the first two principal components: $\square$, esterase A; $\boldsymbol{O}$, esterase B; O, esterase C; $\square$, esterase I. (b) Plot of score of weighted electrophoretic types for the first two principal components: $S$. dysenteriae serotypes 2 to $10 ; \Delta, S$. flexneri serotypes 1 to $5 ; \nabla, S$. flexneri serotype $6 ; \diamond, S$. boydii; $\square, S$. sonnei; $\diamond$, Alkalescens Dispar group; $\nabla$, entero-invasive $E$. coli; O, AIS; $\square$, HIS; $\triangle$, HES. For clarity, some of the allozymes of the various enterases which were projected near the origin of the axes have been omitted from the Figure.

electrophoretic distribution of esterases $A$ and $B$ appeared to be less discriminative than those of esterases $\mathrm{C}$ and $\mathrm{I}$ for differentiation of Shigella from $E$. coli, we analysed the identical $E_{\mathrm{tBA}}$, $E_{\mathrm{tBAC}}, E_{\mathrm{tBAl}}$ and $E_{\mathrm{tBACl}}$ observed in the two organisms. The results were as follows: (i) 168 strains $(26.5 \%)$ of $E$. coli had identical $E_{\mathrm{tBA}}$ with those of Shigella (ii) $35(5.50 \%)$ and $32(5 \%)$ strains of $E$. coli had identical $E_{\mathrm{tBAC}}$ and $E_{\mathrm{tBAl}}$, respectively; and (iii) five strains $(0.78 \%)$ had identical $E_{\mathrm{tBACI}}$. These five strains had one or three null allozymes which reduced the discriminative power of the enzyme analysis.

\section{Principal components analyses}

Three analyses were made: one for Shigella strains and the 636 E. coli strains, one with only Shigella strains, and one with Shigella, the Alkalescens Dispar group and entero-invasive $E$. coli strains. The strains of Shigella boydii serotype 13 and of $S$. dysenteriae serotype 8 that had atypical esterase patterns were not included in these analyses.

Shigella and E. coli strains. The first two principal components accounted for $8 \cdot 14 \%$ of the total variance. Projection of different allozymes (Fig. $1 a$ ) on the first two axes revealed that allozymes A-81, B-72, I-65, C-59, C-61 and C-55 were distinguished by the first component and that the second component opposed allozymes A-78, B-57 and C-60 to allozymes A-75, B-68, B-0, I-68 and C-57. Projection of $W E_{\mathrm{t}}$ (Fig. $1 b$ ) distinguished one group (I) displayed by component 1 , consisting of electrophoretic types recovered from all strains of $S$. flexneri serotype 6, some strains of $S$. boydii, the majority of strains of $S$. sonnei and certain $E$. coli strains, principally those from animal sources; a second group (II), composed of strains of $S$. flexneri serotypes 1 to 5 and some strains of $S$. dysenteriae was opposed by component 2 to a third group (III) composed of HES of E. coli exhibiting allozymes B-57, A-78 and C-60. The remaining strains of $S$. sonnei, $S$. boydii and $S$. dysenteriae were not distinguished by this analysis.

Shigella strains. The first two principal components accounted for $13 \%$ of the total variance. Projections of the allozymes (Fig. 2a) from the first two components revealed that the first component opposed allozymes A-75, B-68 and C-57 to allozymes A-81, B-70 and I-65, and that 

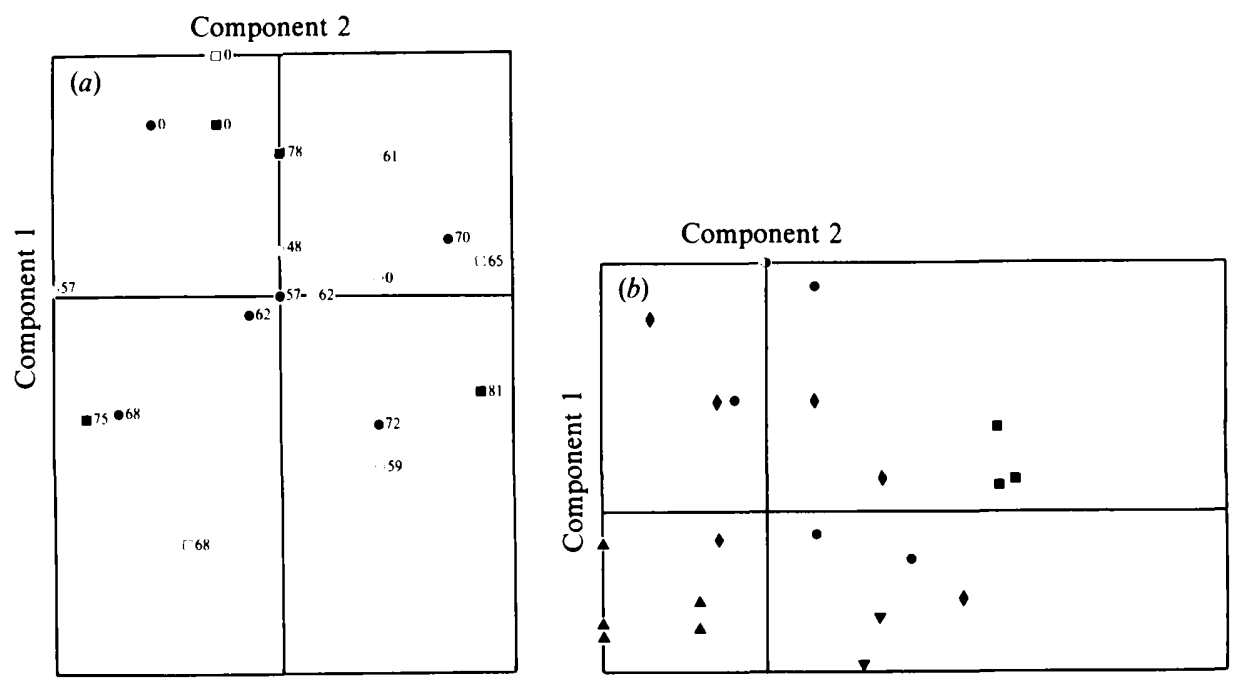

Fig. 2. Principal components analysis of the Shigella strains. (a) Plot of score of allozymes for the first two principal components: symbols as in legend to Fig. 1. (b) Plot of score of weighted electrophoretic types for the first two principal components: $O, S$. dysenteriae serotype 1 ; other symbols as in legend to Fig. 1. For clarity, some of the allozymes of the various esterases which were projected near the origin of the axes have been omitted from the Figure.
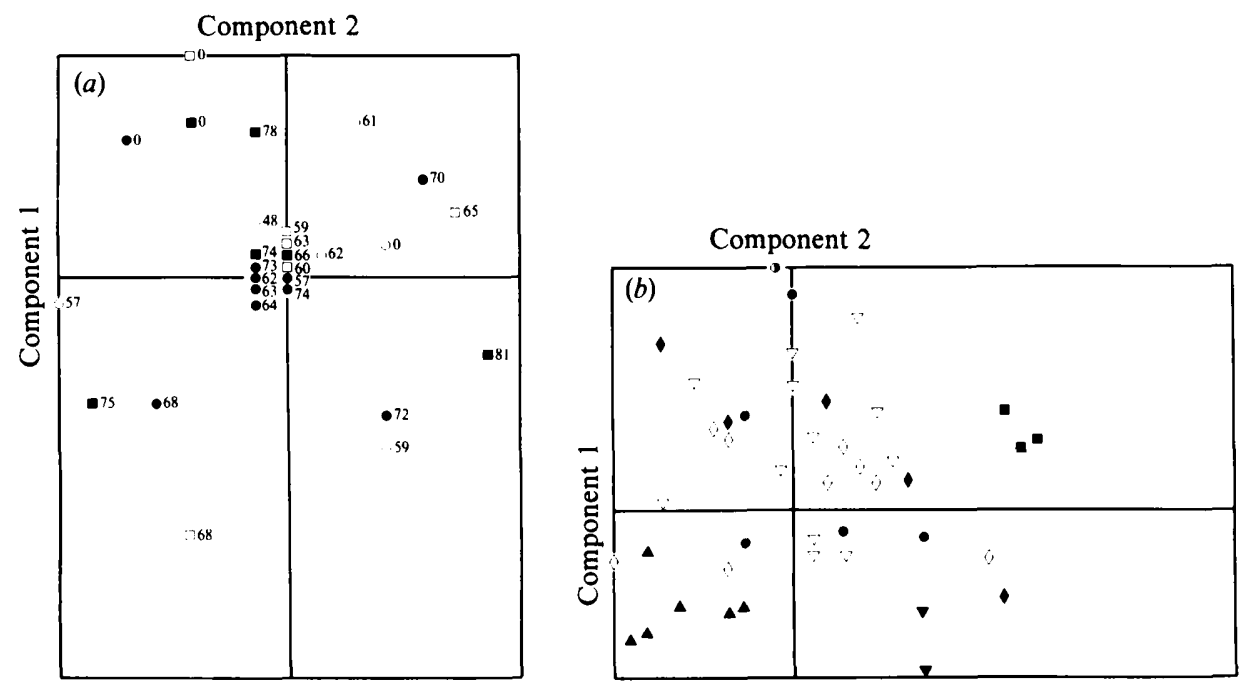

Fig. 3. Principal components analysis of the Shigella strains and of the Alkalescens Dispar group and entero-invasive $E$. coli strains. (a) Plot of score of allozymes for the first two principal components: symbols as in legend to Fig. 1. (b) Plot of score of weighted electrophoretic types for the first two principal components: symbols as in legends to Figs. 1 and 2. For clarity, some of the allozymes of the various esterases which were projected near the origin of the axes have been omitted from the Figure.

the second component opposed allozymes A-0, A-78, B-0, I-0 and C-61 to allozymes I-68, C-59, B-72 and A-81. Projection of $W E_{\mathrm{t}}$ (Fig. $2 b$ ) showed that the first component opposed strains of $S$. flexneri serotypes 1 to 5 to strains of $S$. sonnei, and that the second component opposed strains of $S$. flexneri serotype 6, strains of $S$. boydii serotypes 2 and 4, and a strain of $S$. dysenteriae serotype 7 , to strains of $S$. dysenteriae serotype 1 , and to the remaining strains of $S$.dysenteriae and of $S$. boydii.

Shigella and Alkalescens Dispar group and entero-invasive strains of E. coli. The first two principal components accounted for $11.6 \%$ of the total variance. The projections of allozymes 
Table 6. Discriminant functions $(F)$ used by discriminant analysis to classify the 792 observations within the population of Shigella and the three populations of $E$. coli

\begin{tabular}{|c|c|c|c|c|c|c|}
\hline \multirow[b]{2}{*}{$\begin{array}{l}\text { Allozyme } \\
\text { used }\end{array}$} & \multirow[b]{2}{*}{$F$} & \multirow[b]{2}{*}{$\begin{array}{l}\text { Selection } \\
\text { order }\end{array}$} & \multicolumn{4}{|c|}{ Coefficient } \\
\hline & & & Shigella & $\begin{array}{l}\text { E. coli } \\
\text { HES }\end{array}$ & $\begin{array}{l}\text { E. coli } \\
\text { HIS }\end{array}$ & $\begin{array}{c}\text { E. coli } \\
\text { AIS }\end{array}$ \\
\hline I-68 & $50 \cdot 25$ & 1 & 13.37 & 6.51 & $5 \cdot 33$ & $6 \cdot 60$ \\
\hline$I-65$ & $47 \cdot 70$ & 2 & $15 \cdot 42$ & $3 \cdot 22$ & 1.43 & $2 \cdot 64$ \\
\hline$C-57$ & 44.77 & 7 & 11.07 & 4.48 & 3.41 & 5.97 \\
\hline$C-55$ & 33.87 & 5 & $7 \cdot 02$ & $6 \cdot 16$ & $5 \cdot 50$ & $9 \cdot 51$ \\
\hline$C-61$ & $25 \cdot 33$ & 9 & $15 \cdot 67$ & $6 \cdot 21$ & 6.01 & $7 \cdot 15$ \\
\hline C-59 & $25 \cdot 10$ & 10 & $14 \cdot 25$ & 7.02 & 7.84 & $8 \cdot 32$ \\
\hline B-0 & $20 \cdot 28$ & 3 & 12.05 & 5.96 & $7 \cdot 31$ & $7 \cdot 45$ \\
\hline$A-81$ & 18.93 & 8 & 8.94 & $4 \cdot 31$ & $5 \cdot 63$ & $5 \cdot 76$ \\
\hline$A-0$ & $16 \cdot 22$ & 11 & 4.68 & $5 \cdot 21$ & 4.59 & $9 \cdot 24$ \\
\hline B-70 & 13.75 & 6 & $5 \cdot 68$ & 6.88 & 8.63 & $8 \cdot 38$ \\
\hline B-57 & $10 \cdot 43$ & 4 & $13 \cdot 11$ & $14 \cdot 38$ & $11 \cdot 29$ & $12 \cdot 52$ \\
\hline B-68 & $9 \cdot 64$ & 12 & 8.52 & 5.91 & $8 \cdot 37$ & 7.69 \\
\hline B-74 & 9.00 & 14 & 3.53 & $4 \cdot 60$ & 6.42 & 8.65 \\
\hline C-54 & $8 \cdot 14$ & 15 & 9.04 & $7 \cdot 70$ & $13 \cdot 28$ & $8 \cdot 35$ \\
\hline$C-44$ & 8.01 & 19 & $11 \cdot 57$ & 6.96 & $6 \cdot 36$ & $12 \cdot 61$ \\
\hline$I-60$ & $7 \cdot 52$ & 16 & 1.02 & $1 \cdot 30$ & $4 \cdot 50$ & 1.65 \\
\hline C-48 & $6 \cdot 23$ & 20 & 5.78 & $4 \cdot 35$ & $4 \cdot 70$ & 6.44 \\
\hline $\mathrm{I}-70$ & $6 \cdot 14$ & 13 & 5.42 & $6 \cdot 25$ & 4.87 & $6 \cdot 26$ \\
\hline A-75 & $6 \cdot 10$ & 17 & 3.48 & $2 \cdot 80$ & 4.09 & $2 \cdot 74$ \\
\hline$C-46$ & $5 \cdot 25$ & 21 & 6.57 & $3 \cdot 11$ & 4.86 & $7 \cdot 64$ \\
\hline $\mathrm{I}-0$ & 5.61 & 23 & $7 \cdot 46$ & $5 \cdot 50$ & $5 \cdot 13$ & 5.42 \\
\hline B-60 & $5 \cdot 48$ & 18 & 6.08 & 8.77 & $7 \cdot 55$ & $6 \cdot 18$ \\
\hline$C-56$ & 4.62 & 22 & $3 \cdot 20$ & $7 \cdot 56$ & 5.87 & 9.75 \\
\hline$C-0$ & $4 \cdot 57$ & 24 & $7 \cdot 37$ & $6 \cdot 32$ & $5 \cdot 22$ & 5.95 \\
\hline
\end{tabular}

Table 7. Results of the classification according to discriminant analysis calculations from the 785 observations

Strains of entero-invasive E. coli and of the Alkalescens Dispar group which could not be classified as HES or HIS were not included in the discriminant analysis.

$\begin{array}{lccccc} & \begin{array}{c}\text { Percentage of } \\ \text { strains correctly } \\ \text { classified }\end{array} & \begin{array}{c}\text { Calculated } \\ \text { Shigella }\end{array} & \begin{array}{c}\text { Calculated } \\ \text { HES }\end{array} & \begin{array}{c}\text { Calculated } \\ \text { HIS }\end{array} & \begin{array}{c}\text { Calculated } \\ \text { AIS }\end{array} \\ \begin{array}{l}\text { Shigella } \text { strains (175) } \\ \text { E. coli } \text { strains }\end{array} & 96 \cdot 0 & 168 & 4 & 2 & 1 \\ \text { HES (257) } & 58 \cdot 4 & 12 & 150 & 61 & 34 \\ \text { HIS (142) } & 69 \cdot 7 & 6 & 16 & 99 & 21 \\ \text { AIS (211) } & 61 \cdot 1 & 15 & 17 & 50 & 129 \\ & \text { Total strains } & 201 & 187 & 212 & 185\end{array}$

and of $W E_{\mathrm{t}}$ of Shigella strains (Fig. 3) were similar to those of the preceding analysis. Projection of $W E_{\mathrm{t}}$ did not distinguish any groups corresponding to the Alkalescens Dispar group and entero-invasive $E$. coli strains which displayed a wide distribution throughout the plan. Thus, for the two latter principal component analyses, four major clusters of Shigella strains were distinguished: (i) $S$. dysenteriae serotype 1; (ii) $S$. flexneri serotypes 1 to 5; (iii) $S$. flexneri serotype 6 and $S$. boydii serotypes 2 and 4 and one strain of $S$. dysenteriae serotype 7; and (iv) $S$. sonnei.

\section{Discriminant analysis}

The 785 strains and the 59 allozymes were used in stepwise discriminant analyses to distinguish Shigella strains from AIS, HES and HIS (Tables 6 and 7). Among the 24 allozymes selected for discriminant function (Table 6) the most significant were I-68, I-65, C-57, C-55, C-61 


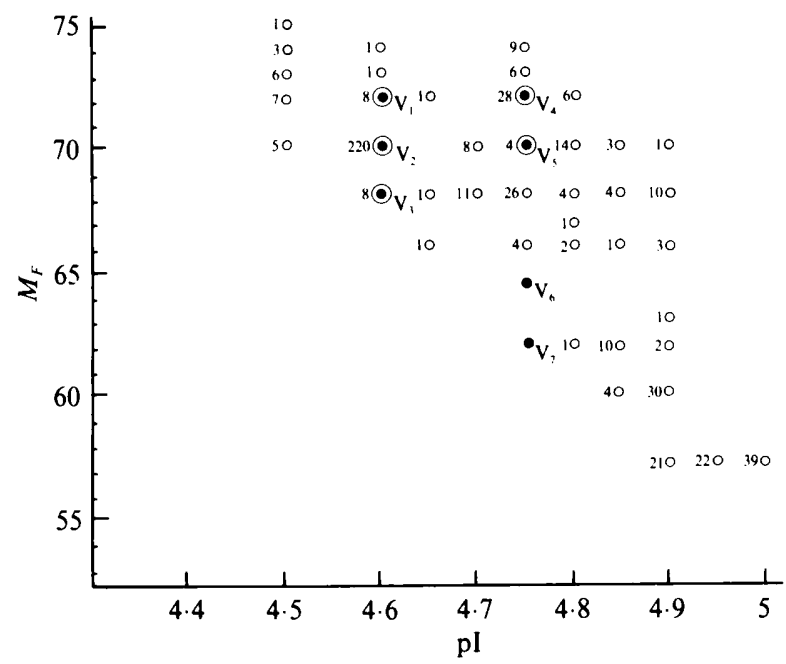

Fig. 4. Two-dimensional electrophoretic profile of esterase B variants of 182 Shigella strains and of 610 $E$. coli strains with the number of isolates of $E$. coli in which each variant is detected. $\bigcirc$, Variant produced by $E$. coli strains; $\odot$, variant produced by Shigella strains; $\odot$, variant produced both by $E$. coli and Shigella strains.

and C-59. As can be seen in the distribution of esterase mobilities, allozymes of esterases I and C appeared to be more significant for distinguishing between Shigella strains and E. coli strains than allozymes of esterases A and B. Application of the discriminant functions (corresponding to the coefficients presented in Table 6) to the 785 strains allowed the correct classification of $96 \%$ of the Shigella strains and of $58.4 \%, 69.7 \%$ and $61.1 \%$ of HES, HIS and AIS of E. coli, respectively (Table 7). Discriminant analysis demonstrated that the Shigella strains were clearly distinguished from the three populations of $E$. coli strains by esterase electrophoretic polymorphism.

\section{Two-dimensional electrophoretic profile of esterase B produced by Shigella strains}

The isoelectric points of esterase B determined by thin-layer IEF were grouped around two points: (i) pI 4.6 for strains of $S$. sonnei and $S$. flexneri serotypes 1 to 5 , one strain of $S$. dysenteriae serotype 10 and three strains of $S$. boydii serotypes 3,6 and 12; and (ii) pl 4.75 for strains of $S$. flexneri serotype 6, two strains of $S$. flexneri serotypes 1 and 3, strains of $S$. boydii serotypes 2 and 4 and one strain of $S$. dysenteriae serotype 7 . Fig. 4 shows the two-dimensional electrophoretic profile (Goullet \& Picard, 1985) established by plotting isoelectric points against electrophoretic mobilities of the esterase B produced by the 182 strains of Shigella and the 610 strains of E. coli. Forty-one and seven distinct electrophoretic variants were defined, both by $\mathrm{pI}$ and $M_{F}$, for $E$. coli and Shigella strains, respectively. Five variants $\left(\mathrm{v}_{1}\right.$ to $\left.\mathrm{v}_{5}\right)$ of Shigella were identical both in $\mathrm{pI}$ and $M_{F}$ values to five variants of pattern $B_{1}$ of $E$. coli (Goullet \& Picard, $1986 b$ ), whereas two variants $\left(v_{6}\right.$ and $\left.v_{7}\right)$ were only observed in Shigella strains. The most frequently observed variants in Shigella strains were $\mathrm{v}_{2}\left(\mathrm{pI} 4 \cdot 6, M_{F} \simeq 70\right)$ for $S$. sonnei strains, $\mathrm{v}_{3}\left(\mathrm{pI} 4 \cdot 6, M_{F} \simeq 68\right)$ for $S$. flexneri serotypes 1 to 5 strains and $\mathrm{v}_{4}\left(\mathrm{pI} 4 \cdot 75, M_{F} \simeq 72\right.$ ) for $S$. flexneri serotype 6 and for some $S$. boydii strains. Variant $\mathrm{v}_{2}$ was the most frequently encountered variant in $E$. coli strains. Variant $\mathrm{v}_{3}$ had the same $\mathrm{pI}$ as $\mathrm{v}_{2}$, but differed in its $\boldsymbol{M}_{F}$. Variant $\mathrm{v}_{4}$ was distinct from the two latter variants according to both electrophoretic parameters (Fig. 4).

\section{Titration curves produced by combined IEF-CE}

Titration curves were used to improve electrophoretic discrimination within each of the three major electrophoretic variants of esterase $B\left(v_{2}, v_{3}\right.$ and $\left.v_{4}\right)$ and between variants $v_{2}$ and $v_{3}$. A single titration curve demonstrating a close molecular relationship between the proteins was 


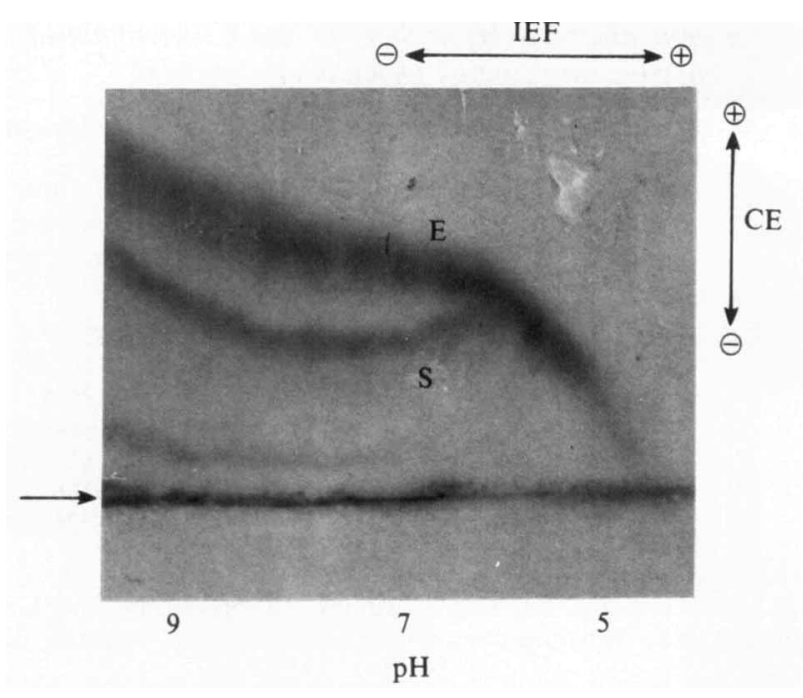

Fig. 5. Comparative titration curves obtained by combined IEF-CE for the most frequent esterase B variant of $E$. coli and for variant $\mathrm{v}_{3}$ of $S$. flexneri strains of serotypes 1 to $5 . \mathrm{S}$, variant $\mathrm{v}_{3}$ of $S$. flexneri serotype 1 (pI 4.6, $M_{F} \simeq 68$ ); $\mathrm{E}$, most frequent variant of $E$. coli (pI 4.6, $M_{F} \simeq 70$ ). The arrow indicates the groove in which the crude enzyme extract was placed (see Methods).

obtained when this method was applied to five strains chosen at random from each of the three variants of Shigella. Similarly, a single titration curve was obtained when variant $\mathrm{v}_{2}$ of $S$. flexneri serotype 6 and variant $v_{2}$ of $S$. boydii serotypes 2 and 4 were titrated together, and another single curve was obtained when each of the three Shigella variants were titrated with the homologous $E$. coli variants. A typical 'fork' form (Fig. 5) was produced when the mobility curves from $v_{3}$ (pI 4.6, $M_{F} \simeq 68$ ) were compared with those of the most frequently occurring $E$. coli variant (pI 4.6, $M_{F} \simeq 70$ ). This may be interpreted as the substitution of a histidine in the $E$. coli variant for an arginine in the $v_{3}$ variant of $S$. flexneri (Rhigetti et al., 1978).

\section{DISCUSSION}

The phenotypic differences between Shigella and E. colistrains have been substantiated at the molecular level by comparative analyses of the esterase polymorphism found in 182 strains of Shigella and 636 strains of $E$. coli. The individual distributions of esterase mobilities (Table 2), comparisons between electrophoretic type (Table 4) and discriminant analysis all indicated that this distinction is principally determined by allozymes of esterases $C$ and I. Shigella variants $\mathbf{v}_{2}$, $\mathrm{v}_{3}$ and $\mathrm{v}_{4}$ of esterase $\mathrm{B}$ showed a close molecular relationship with the three corresponding $E$. coli variants of pattern $B_{1}$, as judged by the single titration curves obtained in each case, while Shigella variants $\mathrm{v}_{6}$ and $\mathrm{v}_{7}$ were distinguished by their $\mathrm{pI}$ from $E$. coli variants of pattern $\mathrm{B}_{2}$ (Goullet \& Picard, 1986b). The absence of esterase pattern $\mathrm{B}_{2}$ in Shigella strains is in agreement with the low proportion of extra-intestinal infections usually observed with these organisms. All the strains of Shigella were differentiated from all those of $E$. coli by distinct electrophoretic profiles. Thus, the six Shigella strains, indistinguishable from $E$. coli strains on the basis of their $E_{\mathrm{tBACl}}$, were distinguished from them by the $\mathrm{pI}$ of esterase B: the strain of $S$. flexneri serotype 1 with the electrophoretic type B-68, A-75, C-0, and I-68 had an esterase pI value of 4.6 while the corresponding strain of $E$. coli had an esterase pI of 4.75. Among strains with electrophoretic type B-72, A-81, C-55 and I-0, esterase B of the strain of $S$. boydii serotype 12 had a pI of 4.6 and the strains of $E$. coli had an esterase pI of 4.75; the four strains of $S$. boydii serotypes 1, 3, and 8 , with electrophoretic type B-72, A-0, C- 0 and I-0 had esterase $\mathrm{pI}$ values of $4 \cdot 75$, and the strain of $E$. coli with the same $E_{\mathrm{t}}$ had an esterase $\mathrm{pI}$ of 4.5. Principal components analyses showed that $S$. flexneri and some $S$. boydii strains were more distantly related to $E$. coli than is $S$. sonnei. This 
Table 8. Comparison of genetic diversity $(H)$ in Shigella and E. coli obtained with esterases and enzymes analysed by Ochman et al. (1983)

$\mathrm{H}=1-\Sigma x_{\mathrm{i}}^{2}$ where $x_{\mathrm{i}}$ is the frequency for each allozyme. The numbers of each allozyme are indicated in parentheses.

No. of strains

No. of electrophoretic types

Mean GDC

GDC esterase B

GDC esterase C

GDC esterase A

GDC esterase I
Esterases

(present study)

\begin{tabular}{cc}
\hline Shigella & E. coli \\
182 & 636 \\
23 & 328 \\
0.687 & 0.822 \\
$0.752(6)$ & $0.820(13)$ \\
$0.748(6)$ & $0.885(19)$ \\
$0.631(4)$ & $0.723(8)$ \\
$0.620(3)$ & $0.860(21)$
\end{tabular}

Other enzymes

(Ochman et al., 1983)

\begin{tabular}{cc}
\hline Shigella & \multicolumn{1}{c}{ E. coli } \\
123 & 1608 \\
23 & \multicolumn{1}{c}{279} \\
$0.588^{*}$ & $0.620^{*}$ \\
MPI+ 0.646(5) & $0.710(9)$ \\
6PG $0.627(6)$ & $0.715(20)$ \\
ACO+ 0.556(4) & $0.616(9)$ \\
IDH+ 0.526(3) & $0.440(6)$
\end{tabular}

* Calculated with 12 enzymes.

† The four most polymorphic enzymes for Shigella strains. (Abbreviations: MPI, mannose phosphate isomerase; 6PG, 6-phosphogluconate dehydrogenase; $\mathrm{ACO}$, aconitase; IDH, isocitrate dehydrogenase.)

observation agrees with the molecular similarity of $\mathrm{v}_{2}$ from $S$. sonnei with the most frequent variant of esterase B produced by $E$. coli strains and confirms the relationship already observed between these organisms. The 12 entero-invasive $E$. coli strains were distinguished from each of the 182 Shigella strains, suggesting that esterase electrophoretic polymorphism is not correlated with the presence of a virulence plasmid in these bacteria (Sansonetti et al., 1983). Table 8 compares the GDCs (Nei, 1975), obtained with Shigella and E. coli strains, of the four esterases and of other enzymes analysed by Ochman et al. (1983). In both studies, the mean GDC is lower for Shigella than for the E. coli strains but the esterases appeared to be more polymorphic than other enzymes in the two organisms.

Principal component analyses of esterase mobilities distinguished four major clusters of Shigella strains corresponding to the following: $S$. dysenteriae serotype $1 ; S$. flexneri serotypes 1 to $5 ; S$. flexneri serotype 6 and $S$. boydii serotypes 2 and 4 ; and $S$. sonnei. Our results are in agreement with those of Dodd \& Jones (1982) who showed that it is possible to distinguish phenotypically at least four taxospecies of Shigella. The distinct esterase pattern of $S$. dysenteriae serotype 1 (Goullet, 1980) is confirmed by the present work showing electrophoretic homogeneity of the 12 strains tested. S. flexneri serotype 6 differs from $S$. flexneri serotypes 1 to 5 by three distinct mobilities and resembles strains of $S$. boydii serotypes 2 and 4 (Goullet, 1980; Goullet et al., 1983). The individual nature of $S$. flexneri serotype 6 as compared to $S$. flexneri serotypes 1 to 5 is supported by the two-dimensional electrophoretic profile of esterase B which showed two distantly related variants $v_{3}$ and $v_{4}$, probably separated by at least three successive mutations for the two clusters of strains (Picard et al., 1987). These findings support the division of strains of serotypes 1 to 5 and serotype 6 into two distinct subphenons (Dodd \& Jones, 1982), and suggest a revision of taxonomic status of strains designated $S$. flexneri serotype 6 (see, e.g., Timakov et al., 1972; Petrovskaya \& Bondarenko, 1977; Dodd \& Jones, 1982; Goullet et al., 1983). S. sonnei appears to be electrophoretically the most homogeneous species and is clearly separated from the other taxospecies of Shigella. Our findings show that the four clusters of Shigella strains as delineated by esterase polymorphism appear to be closer to $E$. coli than to each other and suggest that they are derived from distinct ancestral strains of $E$. coli.

A fifth cluster was represented by strains of $S$. boydii serotype 13 which was clearly distinguished from other Shigella strains both by absence of bands A, B, I and F and by the presence of two additional esterase bands. This correlates well with the work of Brenner et al. (1973, 1982), who showed that $S$. boydii serotype 13 showed low DNA homology with other $S$. boydii serotypes, other Shigella species and $E$. coli. Esterase patterns substantiate the view that this serotype may constitute a new species. The existence of other clusters remains possible but their identification was hampered by the absence of two or three esterase bands or by a limited number of strains. 


\section{REFERENCES}

Brenner, D. J., Fanning, G. R., Skerman, F. J. \& FALKow, S. (1972). Polynucleotide sequence divergence among strains of Escherichia coli and closely related organisms. Journal of Bacteriology 109, 953965.

Brenner, D. J.. Fanning, G. R., Miklos, G. V. \& Steigerwalt, A. G. (1973). Polynucleotide sequence relatedness among Shigella species. International Journal of Systematic Bacteriology 23, $1-7$.

Brenner, D. J., Steigerwalt, A. G., Gail Wathen, H., Gross, R. J. \& Rowe, B. (1982). Confirmation of aerogenic strains of Shigella boydii 13 and further study of Shigella serotypes by DNA relatedness. Journal of Clinical Microbiology 16, 432-436.

DIXON, W. (1981). BMDP statistical software. Berkeley, California: University of California Press.

DoDD, C. E. R. \& JonEs, D. (1982). A numerical taxonomic study of the genus Shigella. Journal of General Microbiology 128, 1933-1957.

Goullet, PH. (1973). An esterase zymogram of Escherichia coli. Journal of General Microbiology 77, 27-35.

Goullet, PH. (1980). Esterase electrophoretic pattern relatedness between Shigella species and Escherichia coli. Journal of General Microbiology 117, 493-500.

Goullet, Ph. \& Picard, B. (1985). A two-dimensional electrophoretic profile for bacterial esterases. Electrophoresis 6, 132-135.

Goullet, Ph. \& Picard, B. (1986a). Comparative esterase electrophoretic polymorphism of Escherichia coli isolates obtained from animal and human sources. Journal of General Microbiology 132, 18431851 .

Goullet, Ph. \& Picard, B. (1986b). Highly pathogenic strains of Escherichia coli revealed by distinct electrophoretic pattern of carboxylesterase B. Journal of General Microbiology 132, 1853-1858.

Goullet, Ph., Picard, B. \& Toucas, M. (1983). Différenciation du serotype 6 des sérotypes $1-5$ de Shigella flexneri par électrophorèse et focalisation isoélectrique de leurs estérases. Annales de microbiologie 134B, 269-276.

Johnson, R., Colwell, R. R., SAKazaki, R. \& TAmURA, K. (1975). Numerical taxonomy, studies of the Enterobacteriaceae. International Journal of Systematic Bacteriology 25, 12-37.
LENNOX, E. S. (1955). Transduction of linked genetic characters of the host by bacteriophage PI. Virology 1, 190-206.

NeI, M. (1975). Molecular Population Genetics and Evolution. New York: Elsevier.

NEI, M. (1978). Estimation of average heterozygosity and genetic distance from a small sample of individuals. Genetics 89, 583-590.

Ochman, H., Whittam, T. S., Caugant, D. A. \& SElander, R. K. (1983). Enzyme polymorphism and genetic population structure in Escherichia coli and Shigella. Journal of General Microbiology 129, 27152726.

Petrovskaya, V. G. \& Bondarenko, V. M. (1977). Recommended corrections to the classification of Shigella flexneri on a genetic basis. International Journal of Systematic Bacteriology 27, 171-175.

Picard, B., Goullet, Ph. \& Krishnamoorthy, R. (1987). A novel approach to study the structural basis of enzyme polymorphism: analysis of carboxylesterase B of E. coli as model. Biochemical Journal 241, 877-881.

Righetti, P. G., Krishnamoorthy, R., Gianazza, E. \& LABIE, D. (1978). Protein titration curves by combined isoelectric focusing-electrophoresis with hemoglobin mutants as models. Journal of Chromatography 166, 455-460.

Sansonetti, P. J., D'Hauteville, H., Ecobichon, C. \& Pourcel, C. (1983). Molecular comparison of virulence plasmids in Shigella and enteroinvasive Escherichia coli. Annales de microbiologie 134A, 295318.

Selander, R. K., Caugant, D. A., Ochman, H., Musser, J. M., Gilmour, M. N. \& Whittam, T. S. (1986). Methods of multilocus enzyme electrophoresis for bacterial population genetics and systematics. Applied and Environmental Microbiology 51, 873-884.

Timakov, V. D., Petrovskaya, V. G., Bondarenko, V. M. \& Khomenko, N. A. (1972). Genetic data concerning Shigella flexneri serotypes 5 and 6 . International Journal of Systematic Bacteriology 22, 149-154.

VERON, M. \& LE MINOR, L. (1975). Nutrition and taxonomy of 'Enterobacteriaceae' and related bacteria. II. General results and classification. Annales de microbiologie 126B, 111-124. 